\title{
Evaluating the Electromyographical Signal During Symmetrical Load Lifting
}

\author{
Jefferson Fagundes Loss ${ }^{1}$, Débora Cantergi ${ }^{1}$, Fábia Milman Krumholz², \\ Marcelo La Torre ${ }^{1,2}$ and Claudia Tarragô Candotti ${ }^{1}$ \\ ${ }_{1}^{1}$ Universidade Federal do Rio Grande do Sul \\ ${ }^{2}$ Universidade do Vale do Rio dos Sinos \\ Brazil
}

\section{Introduction}

Muscular problems account for almost half the cases of work absence, with the back being the region most involved (Kumar, 2011). Bending the trunk forward while performing domestic work or sports related activities is the cause of most back injuries (Fathallah et al., 1998). Small degrees of flexion of the trunk can be considered a medium to high risk factor of injury, mainly when the angle of the forward inclination is greater than 15 degrees and is combined with lifting activities. As the task of lifting objects from the ground exposes spinal structures to muscular-skeletal overload it has been consistently investigated (Simon, 1997). In addition, epidemiological research associates lifting to the risk of developing lumbar back pain (Ferguson \& Marras, 1997; Dolan \& Adams, 1998; Jäger \& Luttmann, 1999; Nachemson, 1999; Wilke et al., 1999; Burdorf, 2000; Kingma et al., 2001; Wilke et al., 2001; Ferguson et al., 2004).

In the early 20th century, the scientific community was already studying back injuries, in particular low back pain (Ghormley, 1933), and its relation with the loads that affect the spine. Due to the invasive nature of measuring these internal loads, models employing indirect means of estimating the loads that act on the lumbar region of the spine during lifting activities began to appear in the 1940s (Wilke et al., 2001). The models found in the literature continue to be primarily concerned with the forces between the muscles, joints and ligaments in only one cross section of the lumbar region (Strait et al., 1947; Cheng, 1998; Gagnon, 2001). While considering the spine as a single rigid structure, these simplified models attempt to provide estimates of what occurs in the spine in situations such as lifting a weight. However, these models are far from representative of the functional anatomical reality of the spine, which consists of several articulated segments and a complex muscle anatomy. The growing interest in producing a more realistic model of the trunk and, consequently, the spine, may have inspired some anthropometric studies (De Leva, 1996; Erdmann, 1997; Zatsiorsky, 2002) to divide the trunk into two or more connected segments. Some models that split the spine into more than one segment are conceived using biomechanical techniques, such as the link segment model (LSM), surface electromyography (EMG) and inverse dynamics (Larivière, 1999; Marras, 1997; La Torre, 2005). The EMG of the trunk muscles has been used as input for biomechanical models that attempt to indirectly estimate the forces acting on the spine (Granata, 1995; Arjmand, 2006). 
A review of the literature reveals that, while the segments of the spine are considered in terms of anatomical division, the overwhelming majority of EMG-based research into lifting is concentrated on the analysis of the lumbar region alone (Alexiev, 1994; Mannion et al., 1997a; Gonçalves \& Barbosa, 2005), while a few have studied the thoracic region (Basler et al., 1997; Lu et al., 2002) and only one study was found that involved positioning electrodes on the cervical region of the spine (Basler et al., 1997). Another problem is that most of these analyses involved various limitations such as the use of devices intended to impose a mechanical restriction on the subjects' movements, activities with limited amplitude or involved no extra load. Specifically in relation to the lifting of symmetrical loads, some studies use electrodes on only one side of the trunk (Toussaint et al., 1995; Dolan \& Adams, 1998). However, though there are those that have collected bilateral signals for different purposes (Nielsen et al., 1998; Granata et al., 1999; Jorgensen \& Marras, 2000; Mirka et al., 2000), and some authors have presented results for right and left muscles (Sheikhzadeh et al., 2008), few studies have actually investigated the electromyographical similarity between the right and left sides.

Considering the above-mentioned issues, the aim of the present study was to investigate the electrical activation of the posterior-medial muscles of the trunk when lifting a load from the floor using a symmetrical movement without mechanical restriction and with electrodes positioned at various levels on both sides of the spine.

\section{The steps and procedures of the electromyographical evaluation}

The study included 16 healthy male individuals. The subjects were right-handers, aged between 20 and 34 years, with mean height of $170.8 \pm 10.4 \mathrm{~cm}$ and mean weight of $67.0 \pm$ $12.5 \mathrm{~kg}$ and no history of spine pathology.

The lifting task started and finished with the individual in a static position without a load and consisted of lifting and lowering an object using both hands, while keeping the knees straight and executing the movement by flexing from the hip. For the purposes of analysis, the gesture was divided into four distinct phases: (1) bending forward without a load (2) lifting the load (3) bending forward with a load (4) returning to the initial position. In the present study, only the data from the load lifting phase were analyzed, because it is the phase which imposes the highest demand on the paraspinal muscles. Together, Figures 1 and 2 illustrate the complete gesture.

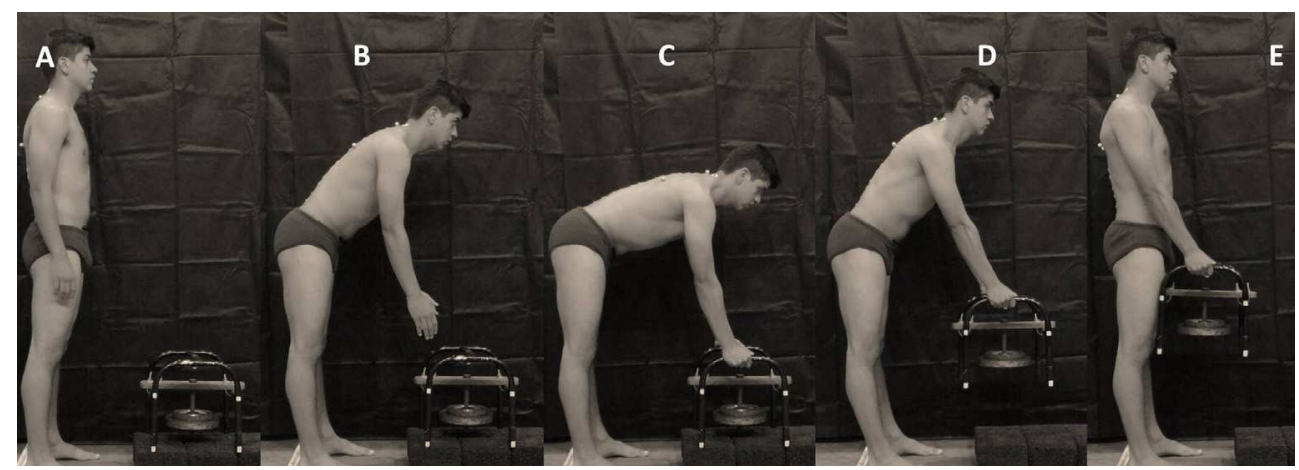

Fig. 1. Phases 1 and 2. The gesture begins with the subject in the standing position (A), the individual bends forward without a load (A to $\mathrm{C}$ ), lifts the load and returns to an upright position with the load (C to E). 


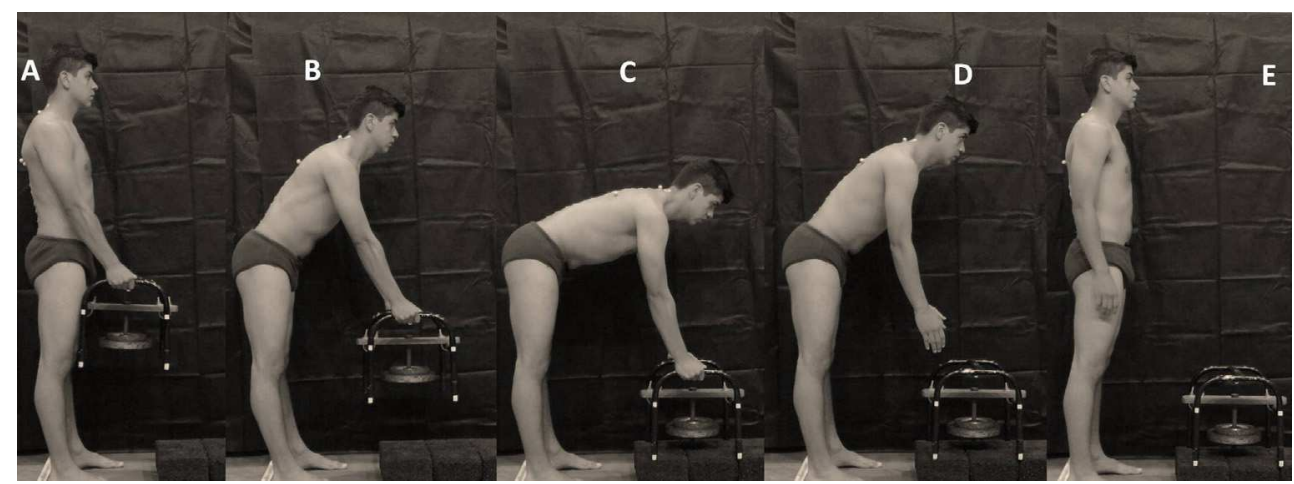

Fig. 2. Phases 3 and 4 . The subject bends forward with a load (A to C), and returns to an upright position without the load (C to E).

The object was a fixed size and positioned at a specific height for each subject (Figure 3A). This was done in order to ensure that the curvatures of the spine remained unchanged while executing the task and to avoid unwanted movements of the pelvis due, for example, to muscle shortening. The load of the attached to the object was determined for each individual by calculating the recommended weight limit established in the Guide to Work Practices for the Handling of Loads from the National Institute for Occupational Safety and Health (NIOSH) (Waters et al., 1994). In this study, the load was equivalent to a Lifting Index (LI) of 1.5. The object consisted of a metal structure with a device for supporting weight plates, which allowed the load on the object to be adapted for each participant in the sample (Figure 3B).

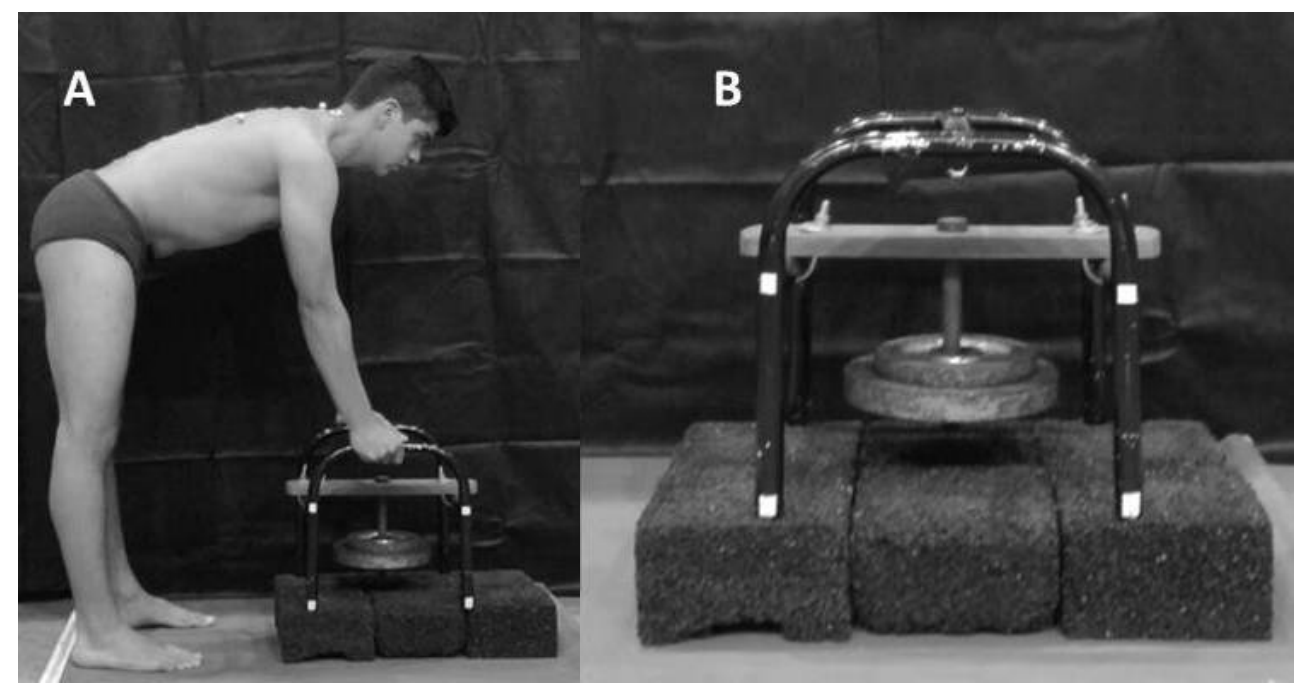

Fig. 3. The lifting task. (A) The object to be lifted is positioned at pre-determined height, according to the individual's anatomical features. (B) The object has a comfortable grip and can be adjusted by including/excluding weight plates like those used in strength training. 
Each participant performed two series of ten repetitions of the analyzed gesture. Four devices were used in order to collect electromyographical data, each one with four channels (Miotool 400, Miotec, Porto Alegre, RS, Brazil), totalling 16 analogical input channels. Signals were collected with a sampling rate of $2000 \mathrm{~Hz}$ per channel, A/D converter of 14 bits, common rejection mode of $110 \mathrm{db}$ (at $60 \mathrm{~Hz}$ ), input impedance of the system was 100 Gohms and a band-pass between 0.1 and $1000 \mathrm{~Hz}$. For the kinematic data acquisition, two digital video cameras were used, with a sampling rate of $50 \mathrm{~Hz}$ (GR-DVL9800, JVC). The images were captured, stored and reconstructed using Dvideow software - Digital Video for Biomechanics for Windows 32 bits (Figueroa et al., 2003). The data from the two systems (EMG and video cameras) were aligned using a device that simultaneously emitted a light signal, which was visible in one of the cameras, and an electrical pulse signal that was captured by the A/D converter, as described elsewhere (Candotti et al., 2008). Figure 4 shows a schematic representation of the distribution and connections of the equipment used for data collection.

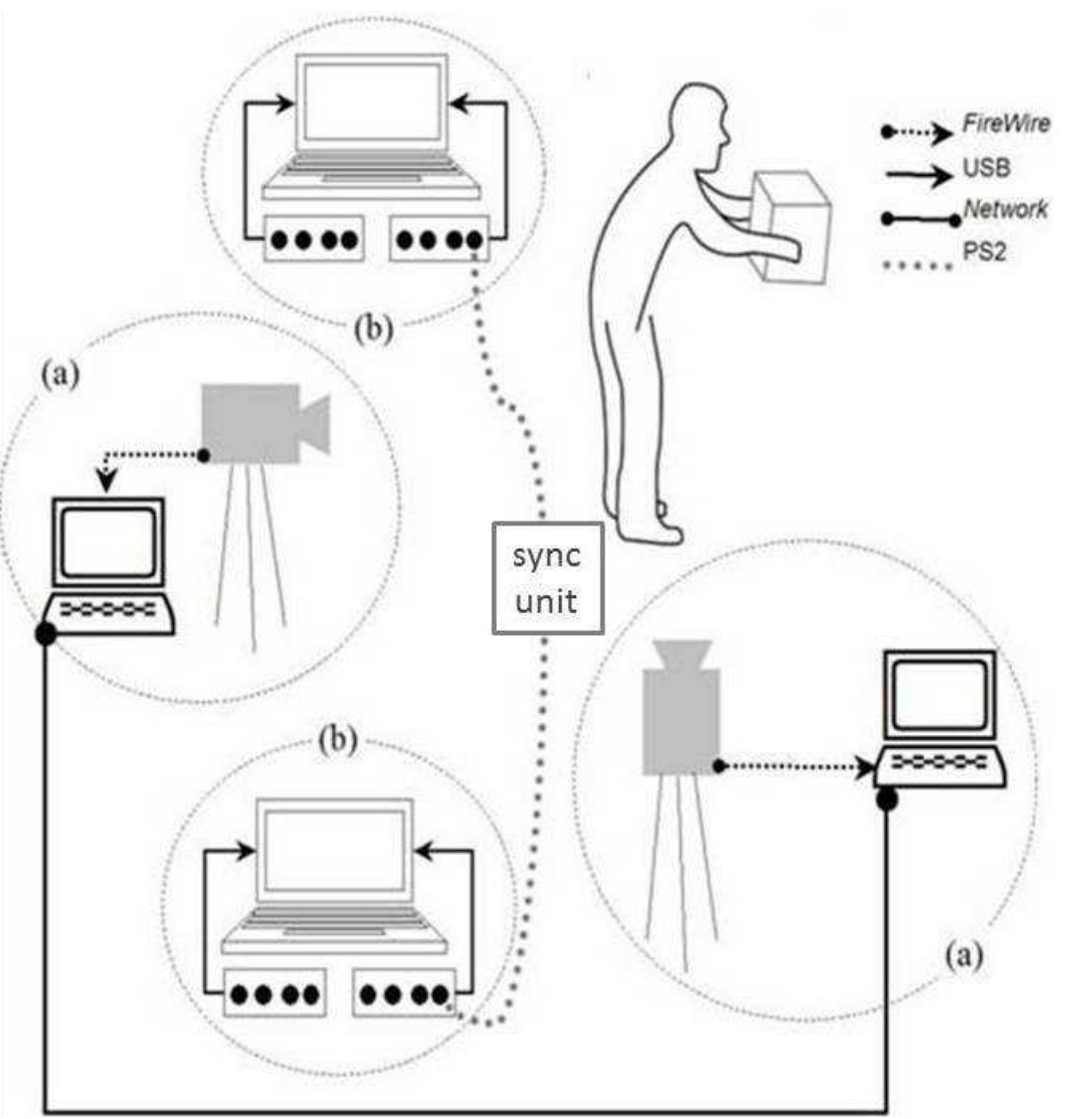

Fig. 4. Schematic representation of the equipment and connections used for the data collection (a) the video cameras connected to the computers, (b) the electromyographical data collection systems. 
The subject's skin was prepared according to the guideline from the SENIAM project (Surface Electromyography for the Non-Invasive Assessment of Muscles www.seniam.org). Fourteen (14) pairs of $10 \mathrm{~mm}$-diameter $\mathrm{Ag} / \mathrm{AgCl}$ surface electrodes (Tyco Healthcare, Mini MediTrace 100 - Kendall), were used in a bipolar configuration, with 20 $\mathrm{mm}$ between the electrodes. They were positioned, according to Basler et al. (1997), bilaterally, with its center $30 \mathrm{~mm}$ from the distal region of the spinal processes of C7, T3, T6, T9, L1, L3 and L5 (Figure 5). Reference electrode was positioned on the right anteriorsuperior iliac spine. Electrode impedance was measured, and considered acceptable when less than $10 \mathrm{kohms.}$

For later normalization of the EMG data, each subject performed two three-second maximum isometric voluntary contractions (MVC) with a two-minute interval between each one. To execute the MVCs, the individuals lay on a table in the decubitus ventralis position with the trunk suspended beyond the edge of the table and the lower limbs strapped to the table with Velcro straps. Manual resistance applied to the back of the head and verbal encouragements were used to ensure that maximum effort was made during each MVC, while the trunk was aligned to the lower limbs. The resistive force during the MVC data collection was assumed to be maximum and symmetrical.

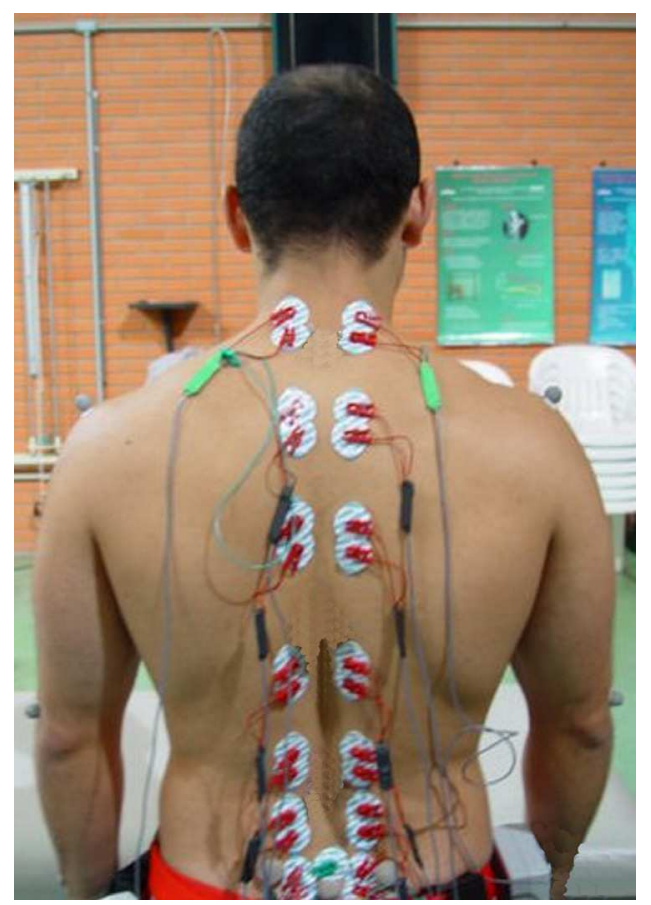

Fig. 5. The positions of the 14 pairs of electrodes placed along the spinal column.

In order to verify the symmetrical execution of the gesture, and divide it into four phases, kinematic data was collected synchronously with the acquisition of the electromyographical data. The phases of the movement were separated using data from digitalized images showing the displacement of the marker placed on T1. Symmetrical execution of the 
movement was confirmed by analyzing the trajectory of the markers placed on the scapulas. In the case that, based on the kinematic trajectory of the markers, the execution was considered to be asymmetrical it was discarded from electromyographical analysis.

The EMG signals from the task and the MVCs were processed using a 3rd order, Butterworth band-pass digital filter, with cut-off frequencies of $20 \mathrm{~Hz}$ and $500 \mathrm{~Hz}$. The EMG signal was then separated according to the movement phases, and the Root Mean Square (RMS) value was calculated. The RMS value of the second phase of the gesture was normalized with the RMS value obtained from the MVC. This normalization generated a percentage of the MVC that was representative of the EMG activity during the execution of phase 2 .

To check the symmetry of the electromyographical signal of each vertebral level between the right and left sides, we used the Wilcoxon test. One-way ANOVA was used to compare the activation between adjacent levels, using the average EMG activity obtained between the right side and left side at each level. In order to identify any differences between the levels and also between the anatomical regions, the behaviour of the EMG signal between vertebral regions was analyzed using a Tukey post-hoc test, according to the anatomical division of the spine into the cervical, dorsal and lumbar spine. The level of significance for all tests was $\mathrm{p}<0.05$.

\section{Symmetry of the electromyographical signal}

The electrical activation of the posterior-medial muscles of the trunk was evaluated during the act of lifting the load from the ground. Similarity between the sides of the spine was only found in the lumbar region at levels L1 and L5 (Figure 6).

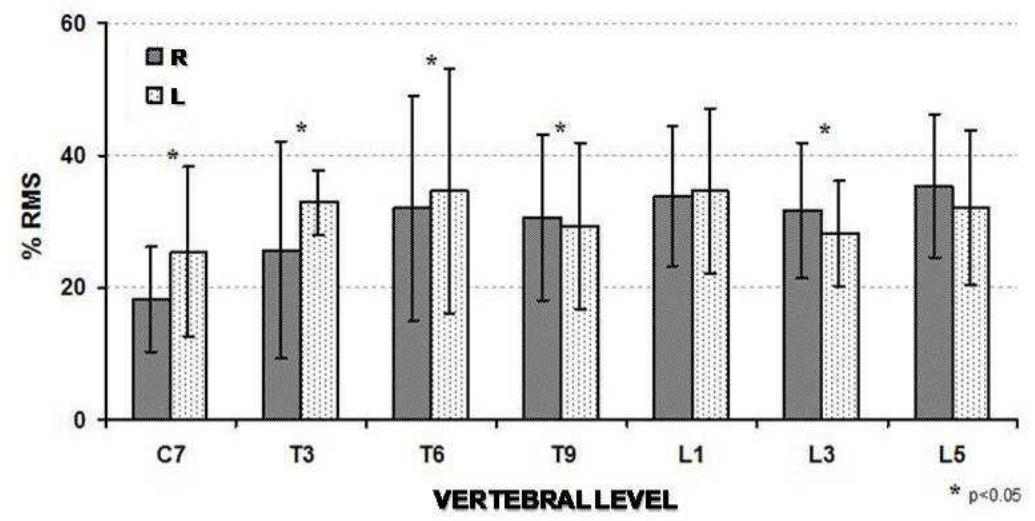

Fig. 6. Means and standard deviations of the electromyographical signal of the symmetrical executions obtained during phase 2 of the act of symmetrical lifting of a load from the ground.

The fact that symmetry was only found to occur at levels L1 and L5 may be related to the anatomy of the spine, particularly the orientation of the facet joints. Facet joints are in the frontal plane in the thoracic spine, permitting rotation, conversely, they are in the sagittal plane in the lumbar spine, providing positive resistance to axial rotations (Qiu et al., 2006). 
Thus, symmetrical movement is facilitated in the lumbar region, while rotational and lateral bending movements are facilitated in the cervical and thoracic regions. Considering this structural feature of the posterior pillar of the functional unit, the lumbar spine has less of a propensity to rotate when compared to cervical and dorsal regions. This characteristic implies that the higher the vertebral level, the greater the need for muscle action in order to avoid unwanted movements during the execution of a symmetrical movement (Neumann, 2002).

Figures 7, 8 and 9 illustrate the comparison of the behaviour of electrical activity between right and left sides in each execution of phase 2 of the gesture performed by a single member of the sample. Considering the anatomy of each region, the asymmetry displayed in the upper levels may be related to greater potential to rotate of the thoracic and cervical regions due to the spatial positioning of their facet joint. This factor may explain the similarity between the sides in the lumbar level activation, which may be related to the restricted degree of freedom in this region of the spine in relation to this movement.

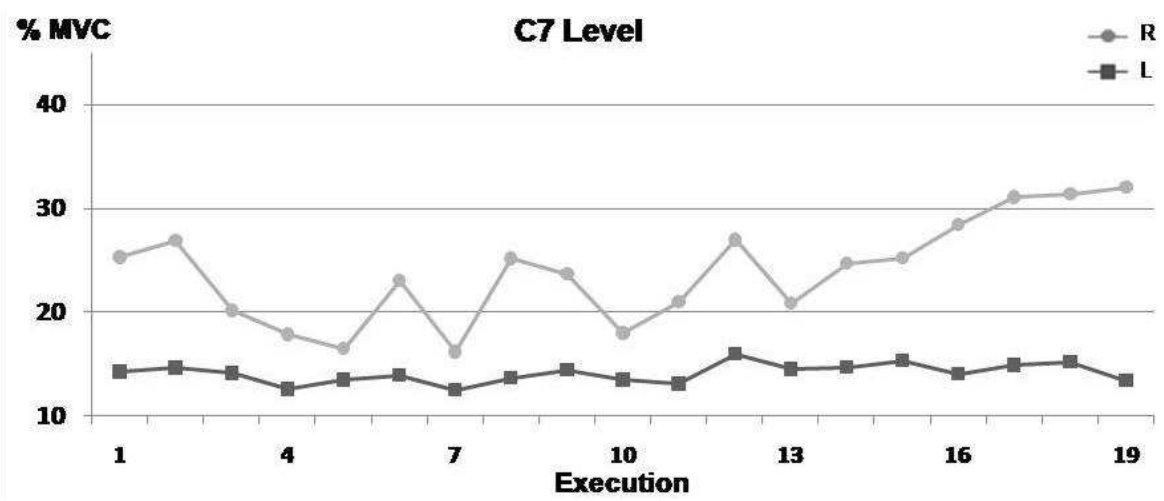

Fig. 7. Comparison of electromyographical activity between right and left sides, at the C7 level in phase 2 of the gesture of symmetrical lifting of a load from the ground, showing all the executions of an individual.

Furthermore, considering the Systems Model of Balance theory, Umphred (1995) explained the necessity for subject/task/ambient interaction in order for dynamic balance to occur. In this model, peripheral and central components act on the motor planning and execution systems at the same time as the sensorial stimulus and the processing system. So sufficient movement is generated in order to maintain balance and perform the task (Thelen, 1989; Umphred, 1995). Muscle actions that help control the symmetry of the movement are automatic postural responses that allow continuous unconscious balance control during the execution of volitional movements. It is speculated that automatic postural responses occur due to the information obtained from the System Model of Balance. These characteristics related to mobility may explain the findings of the present study, in which symmetry was only found at levels L5 and L3.

While the task in the present study was designed to be performed freely, without any apparatus to limit movement, thus mimicking as closely as possible the way in which this task is performed by individuals in their daily activities, some studies, when investigating the occurrence of activation symmetry, have used data obtained from isometric tasks performed with the use of mechanical limitations intended to ensure symmetrical execution 
of the movement. Alexiev (1994) found symmetry in 40 individuals and Mannion et al. (1997b) in 34 individuals, and in both studies, the samples consisted of individuals who had no complaint of lumbar pain. Golçalves and Barbosa (2005) also used a healthy, though smaller, sample and found symmetrical activation of the lumbar muscles while researching for data on muscle fatigue. In all the above-mentioned studies data were collected exclusively from the lumbar region.

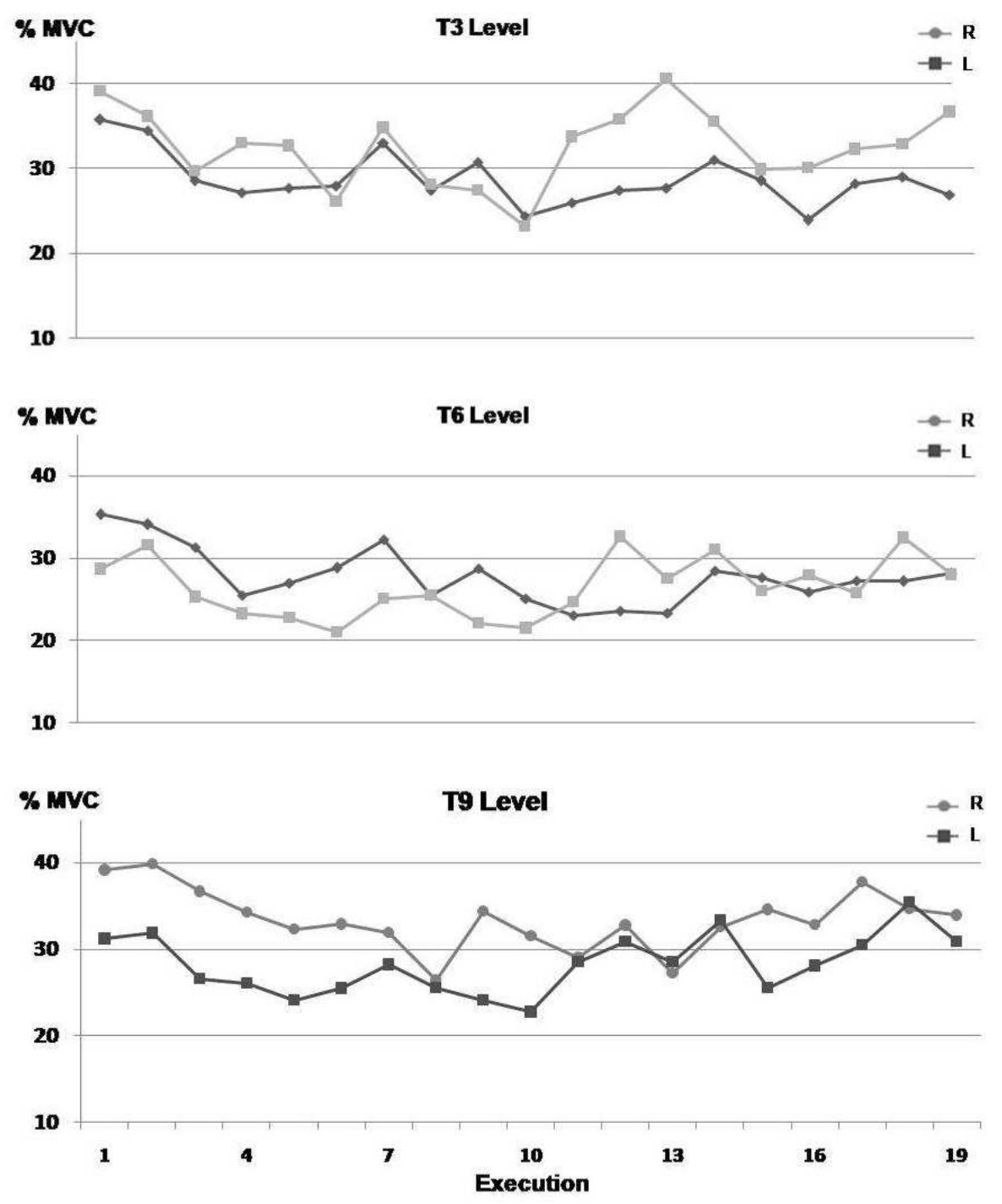

Fig. 8. Comparison of electromyographical activity between right and left sides, at the T3, T6 and T9 levels in phase 2 of the gesture of symmetrical lifting of a load from the ground, showing all the executions of an individual. 

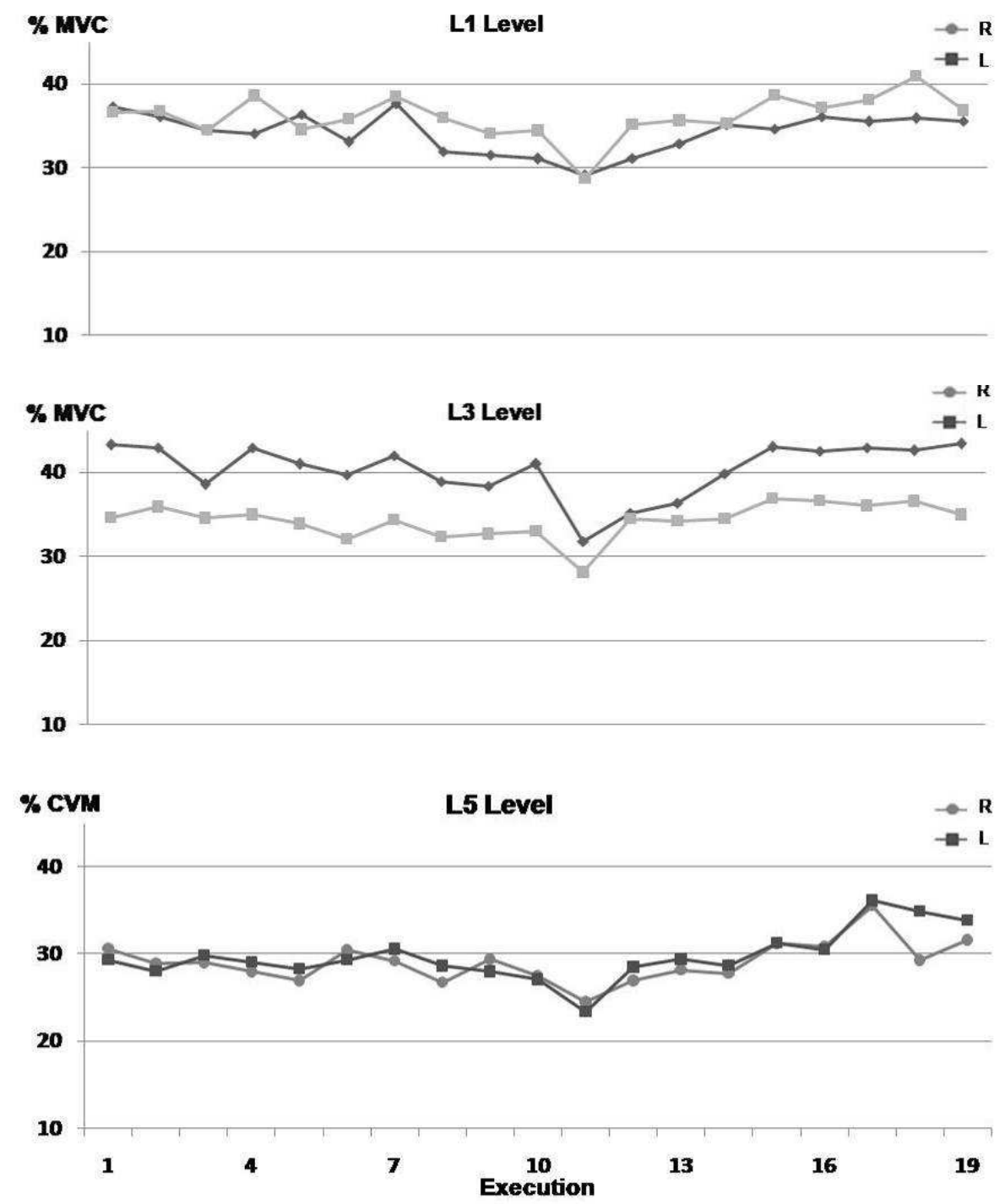

Fig. 9. Comparison of electromyographical activity between right and left sides, at the L1, L3 and L5 levels in phase 2 of the gesture of symmetrical lifting of a load from the ground, showing all the executions of an individual.

Basler et al. (1997) and Lu et al. (2002) investigated the thoracic and cervical regions. The first study analysed the C3-C4, T1, T6 and T9 levels, as well as L3 level, but, in their protocol, the electromyographic signal was captured during isometric contractions without load, with posture correction both in orthostatic and sitting posture. In the second study, electrical activation at the T3-T4, T10-T11 and L2-L3 levels was analyzed during the performance of only two repetitions of the movement without load. Although the latter study did not 
use any device to ensure execution symmetry, the low number of repetitions made verification easy.

In other studies involving only the lumbar level, the movements were limited to isometric contractions or dynamic activities with mechanical restrictions, which may have influenced the results (Alexiev, 1994; Lu et al., 2002). Only Nouwen et al. (1987) found asymmetry of the activation in the lumbar region in individuals both with and without pain. In that study, the participants performed trunk flexion and extension while having their pelvis held by the examiner.

Thus, when the posterior-medial muscles of the trunk are analyzed during a task involving the symmetrical flexion-extension of the trunk, activation symmetry is only seen in the lumbar region, and this symmetry is more evident the lower the vertebral level being studied. Hence, it may be suggested that studies that analyze the upper levels of the vertebral spine should place electrodes bilaterally, even when the movement is considered symmetrical, while those that study the lumbar level, specially the lower levels, may place them unilaterally.

\section{Comparison between the vertebral levels and description of the electrical behavior of different segments of the spine}

In order to compare the different vertebral levels, the arithmetic average between the activation of the right and left sides was calculated. Figure 10 shows the average values corresponding to the activation during the load-lifting phase. Similarity in behaviour was only found between the adjacent levels T6-T9 and L3-L5. It should be noted that comparisons were only made between adjacent levels, as there was no justification for comparisons between distant regions. The EMG signal captured in the cervical region showed the lowest level of activation (approximately 22\%), probably due to the relative noninvolvement of this region in the effect produced by overload imposed by the activity under study.

No data were found in the literature that compared activation between so many vertebral levels. Gonçalves and Barbosa (2005) conducted a study of fatigue-induction using electrodes at levels L2-L3 and L4-L5 and found higher levels of fatigue in the lower region, but they did not relate this finding with a higher degree of electrical activation, but to a predominance of type II muscle fibres, which are less resistant to fatigue. It should also be noted that the greater rhomboid muscle inserts on the spinous process of fifth thoracic vertebra, and thus there may have been a cross-talk effect, due to the need to stabilize the scapulas. However, on the other hand, interestingly, it is in this region that the apex of thoracic kyphosis is found. In contrast, the apex of the lumbar curvature, L3, is precisely the lumbar level with the lowest activation.

These results enable us to identify a non-homogeneous behaviour between adjacent levels. That is, while some comparisons between levels were similar, others presented differentiated muscular demands. Moreover, there was no pattern of increasing or decreasing behaviour along the spine. From this perspective there seems to be no pattern of activation throughout the various levels analyzed during the concentric phase of the symmetrical load lifting task. However, information regarding the intensity of the EMG signal from the posterior-medial muscles of the spine may help in developing models that provide information regarding the load on the spine. 


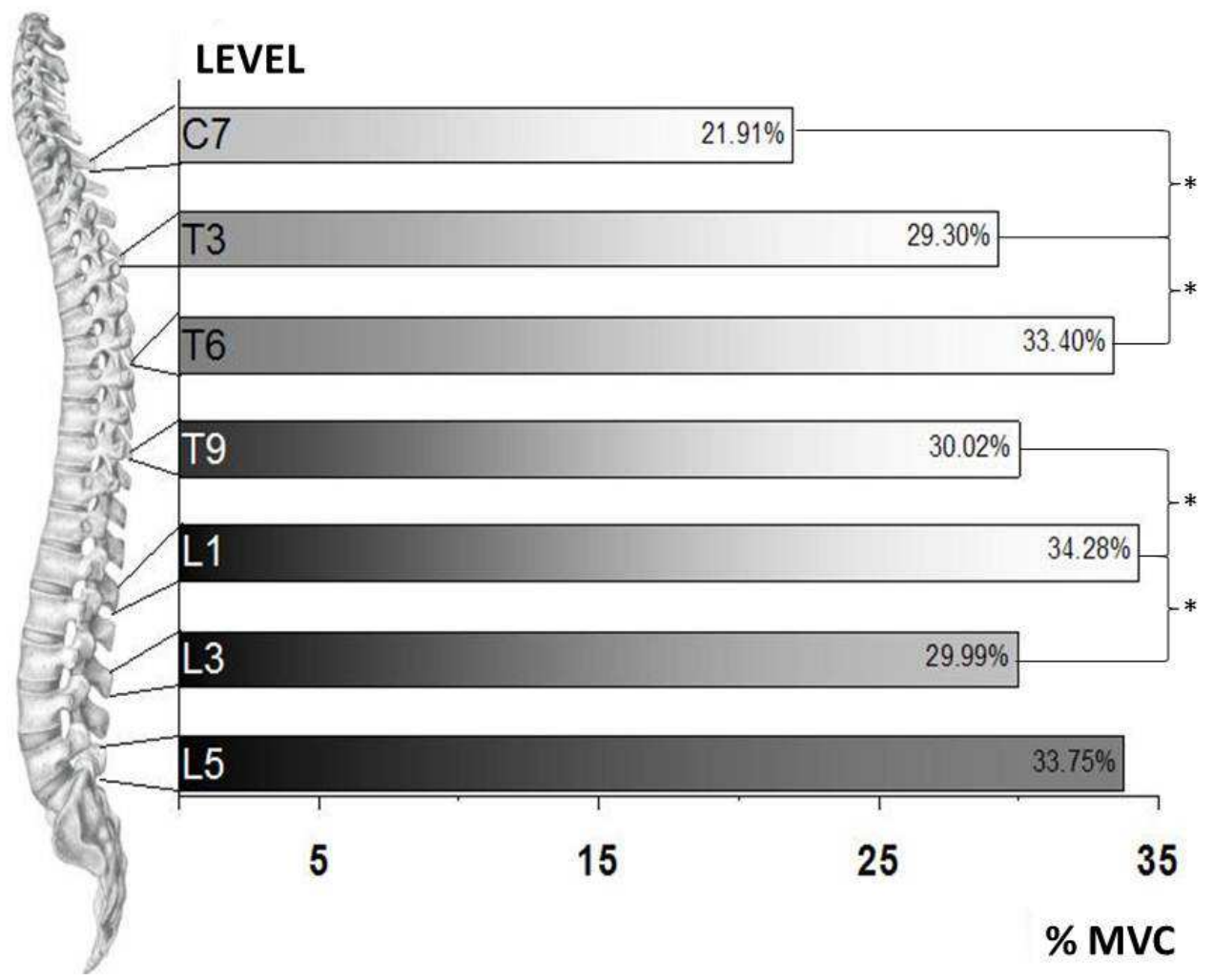

Fig. 10. Mean electrical activation between right and left sides in the seven vertebral levels for all symmetrical executions in phase 2 and their relationship with the sagittal curvatures of the spine. * Significant difference between the marked levels $(\mathrm{p}<0.05)$.

It is of great importance to understand the loads imposed on the spine, since these are considered a major risk factor for the acceleration of intervertebral disc degeneration (Wilke et al., 2001). Thus, the scientific community that studies the loads imposed on the spine has developed several methods of measuring or estimating their magnitude. One such method makes use of the EMG technique. Assuming that the muscle force developed by a given muscle contraction depends on the neural excitation applied, the EMG can be considered an indicator of strength. Consequently, different types of biomechanical models of the lumbar spine have used EMG to indirectly estimate the load on the spine during lifting tasks (Granata, 1995; Kingma et al., 1996; Gagnon, 2001; Kingma, 2004; Arjmand, 2006).

According to Dolan et al. (1999), the indirect methods that use biomechanical models to measure loads on the spine can be divided into two basic categories: (1) those that measure the acceleration of body parts and use Link Segment Model (LSM) and (2) those that attempt to directly measure muscle strength by calibrating the electromyographical signal (EMG Models). In addition, there are Hybrids that combine LSM with EMG Models. EMG-assisted models for evaluating dynamic movement have been introduced based on the concept that the EMG signal is a continuous measure of muscle activity, and may be used as a basis for determining the force generating history (Marras et al., 1997). 
McGill and Norman (1986) developed a dynamic musculoskeletal model of the lumbar spine that incorporates great three-dimensional detail of the ligaments of musculoskeletal system. The model predicted the resultant moment in the intervertebral articulation between the fourth and fifth lumbar vertebrae (L4-L5) allowing a rough estimate of the compression and shearing forces. The resultant moment obtained using the LSM-3D was divided into separate muscle, ligament and joint components based on information from the literature, radiological archives and the use EMG of techniques. The model was used to analyze the performance of tasks involving the symmetrical lifting of an object from the ground, executed by simultaneous flexion of the hip and knee.

Dolan and Adams (1993) analyzed the compressive forces on the lumbar spine using an EMG-assisted model. The model considered the muscular activity of agonist and antagonist muscles during the movement, as well as aspects related to the speed of contraction, the force-length and force-velocity relationships. The model was evaluated by comparing the results of the trunk extensor moment, obtained from an LSM associated with the inverse solution with the results predicted by the model based on the electromyographic signal.

An auxiliary electromyographic model was developed by Granata and Marras (1995), using information on the muscle activity (EMG), specific tension, physiological cross-sectional area (PCSA) and the force-length and force-velocity relationships to calculate the muscle strength of trunk muscles and the erector joint force at L5-S1. According to Granata and Marras (1995), the main advantage of this model over the LSM, is that it shows the influence of muscle coactivation on the results of compressive strength during the lift.

Dijke et al. (1999) implemented a biomechanical model of load transference from the spine to the pelvis and legs, taking into account the influence of muscles, ligaments and different postures. The geometric data from the model were obtained using Magnetic Resonance Imaging (MRI), which enabled the muscles and ligaments to be modelled in terms of vector forces. The model was characterized as static and three-dimensional. The agonist muscle activity predicted by the model corresponded to the values for electromyographical activity found in the literature.

Considering the possibility of using the results of the present study in models that use electromyography to estimate the forces acting within the spine, and given that there was no activation pattern between the different levels that were analyzed, we attempted to group the various levels into regions to minimize the variability of the signal obtained. For this purpose the established anatomical regions were considered, so that the electrode placed at the C7 level represented the cervical region, the electrodes placed at T3, T6 and T9 represented the thoracic region, and the electrodes placed at L1, L3 and L5 represented the lumbar region. To represent each region, a value was calculated based on the arithmetic mean of the values of each pair of electrodes representing its respective region.

The activation in the cervical region was $21.8 \%$ of the MVC, in the thoracic region it was $30.8 \%$, and in the lumbar region it was $32.6 \%$ (see Table 1). When analyzing the average EMG levels collected from each region, significant differences were found between all the regions compared $(\mathrm{p}<0.05)$. Furthermore, the activation was found to increase from top to bottom; that is, the level of electrical activation is greater when a lower region is compared with that located immediately above it.

If, on the one hand, the results of this study cannot be directly used to implement an EMGaided model of the spine, on the other the grouping by regions (cervical, thoracic and lumbar) suggests that it is feasible to divide the column in at least three levels. In the same way as there is a classical anatomical division of the spine into these three regions, 


\begin{tabular}{cccc}
\hline \multirow{2}{*}{ Region } & \multirow{2}{*}{ Mean Activation } & \multicolumn{2}{c}{ Confidence Interval = 95\% } \\
\cline { 3 - 4 } & & Lower Limit & Upper Limit \\
\hline Cervical & $21.85^{\mathrm{a}}$ & 20.03 & 23.67 \\
\hline Thoracic & $30.85^{\mathrm{b}}$ & 29.80 & 31.90 \\
\hline Lumbar & $32.63^{\mathrm{c}}$ & 31.58 & 33.68 \\
\hline
\end{tabular}

Table 1. Mean values for electrical activation (\% of MVC) of the posterior-medial muscles of the spine, grouped into three segments: cervical, thoracic and lumbar. Different letters indicate a difference compared to the other regions.

Zatsiorsky (2002) divided the trunk into three regions and provided anthropometric data for each region. With this in mind, electromyographical monitoring of the posterior-medial trunk muscles seems to provide the means to model the spine in three regions as an alternative to a rigid structure.

\section{Conclusions}

This study has found that when comparing the electrical activation of the right and left sides of the spine at seven vertebral levels in the cervical, thoracic and lumbar spine while symmetrically lifting a load from the ground, similarity only occurs in part of the lumbar levels. When comparing the mean electrical activation between the different levels during the same gesture it was also found that the electrical activation increases from highest to the lowest studied region, so that the percentage of activation is higher in the lumbar region than in the thoracic region, which in turn, has a higher activation than the cervical level.

Given the highly complex nature of the joint and muscle structures that make up the spine, most of the models found in the literature only provide the results of internal loads on the lumbar spine. The models presented above, despite using detailed views of the muscle and joint structures, are limited by the fact that they consider the spine as a rigid structure, using a single rotating axis, while in reality the column is divided into 7 cervical, 12 thoracic, 5 lumbar and 5 sacral vertebrae, as well as the coccyx and sacrum, and is articulated between each two vertebrae, particularly in three upper areas. Thus, it is understood that the next step in model development will be to split the spine into more segments.

While there are studies that seek to understand the spine as a whole, and include the cervical, thoracic and lumbar spine, studies of the internal loads on the spine are usually limited to the lumbar region. Although most cases of back injury involve the lumbar region, there are also complaints of pain in other regions of the trunk. A model that divides the spine into more segments, while not reflecting the total number of vertebrae in the spine, would bring the study of the internal loads in the spine closer to reality. The results of this study together with those of other anthropometric and anatomical studies provide a contribution towards future studies aimed at creating models of the spine that include more segments, which will in all likelihood provide better estimates of what is happening internally in the spine.

\section{Acknowledgements}

We thank Miotec Equipamentos Biomédicos Ltda for the loan of the electromyographical equipment and for their technical support during data collection. 


\section{References}

Alexiev, A. R. (1994). Some differences of the electromyographic erector spinae activity between normal subjects and low back pain patients during the generation of isometric trunk torque Electromyography and clinical neurophysiology 34(8): 495-499,

Arjmand, N. S.-A., A. (2006). Model and in vivo studies on human trunk load partitioning and stability in isometric forward flexions Journal of biomechanics 39(3): 510-521,

Basler, H. D., Keller, S. \& Herda, C. (1997). Good postural habits: A pilot investigation using emg scanning of the paraspinals Applied psychophysiology and biofeedback 22(3): 171182 ,

Burdorf, A. (2000). Work-related musculoskeletal disorders Annals of Occupational Hygiene 44(3), 0003-4878

Candotti, C. T., Loss, J. F., Bagatini, D., Soares, D. P., Da Rocha, E. K., De Oliveira, Á. \& Guimarães, A. C. S. (2008). Cocontraction and economy of triathletes and cyclists at different cadences during cycling motion Journal of Electromyography and Kinesiology,

Cheng, C. K., Chen, H. H., Et Al. (1998). A three-dimensional mathematical model for predicting spinal joint force distribution during manual liftings Clinical Biomechanics 13(1): 1223-1230,

De Leva, P. (1996). Adjustments to zatsiorsky-seluyanov's segment inertia parameters Journal of biomechanics 13(1): 1223-1230,

Dijke, G. a. H. V., Snijders, C. J., Stoeckart, R. \& Stam, H. J. (1999). A biomechanical model on muscle forces in the transfer of spinal load to the pelvis and legs Journal of biomechanics 32(9): 927-933, 0021-9290

Dolan, P. \& Adams, M. A. (1998). Repetitive lifting tasks fatigue the back muscles and increase the bending moment acting on the lumbar spine Journal of biomechanics 31(8): 713-721,

Dolan, P., Kingma, I., Van Dieen, J., De Looze, M. P., Toussaint, H. M., Baten, C. \& Adams, M. A. (1999). Dynamic forces acting on the lumbar spine during manual handling: Can they be estimated using electromyographic techniques alone? Spine 24(7): 698$703,0362-2436$

Dolan, P. A., M. (1993). The relationship between emg activity and extensor moment generation in the erector spinae muscles during bending and lifting activities Journal of biomechanics 26(4-5): 513-522,

Erdmann, W. S. (1997). Geometric and inertial data of the trunk in adult males Journal of biomechanics 30(7): 679-688,

Fathallah, F. A., Marras, W. S. \& Parnianpour, M. (1998). An assessment of complex spinal loads during dynamic lifting tasks Spine 23(6): 706, 0362-2436

Ferguson, S. \& Marras, W. (1997). A literature review of low back disorder surveillance measures and risk factors Clinical Biomechanics 12(4): 211-226, 0268-0033

Ferguson, S. A., Marras, W. S. \& Burr, D. L. (2004). The influence of individual low back health status on workplace trunk kinematics and risk of low back disorder Ergonomics 47(11): 1226-1237, 0014-0139

Figueroa, P. J., Leite, N. J. \& Barros, R. M. L. (2003). A flexible software for tracking of markers used in human motion analysis Computer methods and programs in biomedicine 72(2): 155-165, 
Gagnon, D., Larivière, C., Et Al. (2001). Comparative ability of emg, optimization, and hybrid modelling approaches to predict trunk muscle forces and lumbar spine loading during dynamic sagittal plane lifting Clinical Biomechanics 16(5): 359-372,

Ghormley, R. K. (1933). Low back pain: With special reference to the articular facets, with presentation of an operative procedure Journal of the American Medical Association 101(23): 1773, 0098-7484

Gonçalves, M. \& Barbosa, F. S. S. (2005). Análise de parâmetros de força e resistência dos músculos eretores da espinha lombar durante a realização de exercício isométrico em diferentes níveis de esforço Revista Brasileira de Medicina do Esporte 11(2): 109114 ,

Granata, K., Marras, W. \& Davis, K. (1999). Variation in spinal load and trunk dynamics during repeated lifting exertions Clinical Biomechanics 14(6): 367-375,

Granata, K. P. M., W. (1995). An emg-assisted model of trunk loading during free-dynamic lifting Journal of biomechanics 28(11): 1309-1317,

Jäger, M. \& Luttmann, A. (1999). Critical survey on the biomechanical criterion in the niosh method for the design and evaluation of manual lifting tasks International journal of industrial ergonomics 23(4): 331-337, 0169-8141

Jorgensen, M. \& Marras, W. (2000). The effect of lumbar back support tension on trunk muscle activity Clinical Biomechanics 15(4): 292-294,

Kingma, I., Baten, C., Dolan, P., Toussaint, H., Van Dieën, J., De Looze, M. \& Adams, M. (2001). Lumbar loading during lifting: A comparative study of three measurement techniques Journal of Electromyography and Kinesiology 11(5): 337,

Kingma, I., De Looze, M., Toussaint, H., Klijnsma, H. \& Bruijnen, T. (1996). Validation of a full body 3-d dynamic linked segment model Human Movement Science 15(6): 833860 ,

Kingma, I. V. D., J. H. (2004). Lifting over an obstacle: Effects of one-handed lifting and hand support on trunk kinematics and low back loading Journal of biomechanics 37(2): 249255,

Kumar, S. (2001). Theories of musculoskeletal injury causation Ergonomics 44(1): 17-47,

La Torre, M., De Oliveira Melo, M., Et Al. (2005). Cálculo das forças internas na coluna lombar através da técnica da dinâmica inversa revista brasileira de ciências do esporte 29(2),

Larivière, C. G., D. (1999). The influence of trunk modelling in 3d biomechanical analysis of simple and complex lifting tasks Clinical Biomechanics 14(7): 449-461,

Lu, W. W., Hu, Y., Luk, K. D. K., Cheung, K. \& Leong, J. C. Y. (2002). Paraspinal muscle activities of patients with scoliosis after spine fusion: An electromyographic study Spine 27(11): 1180,

Mannion, A. F., Connolly, B., Wood, K. \& Dolan, P. (1997a). The use of surface enig power spectral analysis in the evaluation of back muscle function Journal of Rehabilitation Research and Development 34(4): 427-439,

Mannion, A. F., Dumas, G. A., Cooper, R. G., Espinosa, F. J., Faris, M. W. \& Stevenson, J. M. (1997b). Muscle fibre size and type distribution in thoracic and lumbar regions of erector spinae in healthy subjects without low back pain: Normal values and sex differences Journal of Anatomy 190(04): 505-513,

Marras, W. S. G., K. P. (1997). The development of an emg-assisted model to assess spine loading during whole-body free-dynamic lifting Journal of Electromyography and Kinesiology 7(4): 259-268, 
Mcgill, S. \& Norman, R. (1986). Partitioning of the 14-15 dynamic moment into disc, ligamentous, and muscular components during lifting Spine 11(7): 666, 0362-2436

Mirka, G., Glasscock, N., Stanfield, P. \& Wilson, J. (2000). An empirical approach to characterizing trunk muscle coactivation using simulation input modeling techniques Journal of biomechanics 33(12): 1701-1704,

Nachemson, A. (1999). Back pain: Delimiting the problem in the next millennium International journal of law and psychiatry 22(5-6): 473, 0160-2527

Neumann, D. A. (2002). Kinesiology of the musculoskeletal system: Foundations for physical rehabilitation Mosby, 0815163495 , St. Louis

Nielsen, P., Andersen, L. \& Jørgensen, K. (1998). The muscular load on the lower back and shoulders due to lifting at different lifting heights and frequencies Applied Ergonomics 29(6): 445-450,

Nouwen, A., Van Akkerveeken, P. F. \& Versloot, J. M. (1987). Patterns of muscular activity during movement in patients with chronic low-back pain Spine 12(8): 777,

Qiu, T. X., Teo, E. C. \& Zhang, Q. H. (2006). Comparison of kinematics between thoracolumbar $\mathrm{t} 11-\mathrm{t} 12$ and $\mathrm{t} 12-11$ functional spinal units Proceedings of the Institution of Mechanical Engineers, Part H: Journal of Engineering in Medicine 220(4): 493-504, 0954-4119

Sheikhzadeh, A., Parnianpour, M. \& Nordin, M. (2008). Capability and recruitment patterns of trunk during isometric uniaxial and biaxial upright exertion Clinical Biomechanics 23(5): 527-535,

Simon, M. H., Brogmus, G.E., Courtney, T.K. (1997). Low back pain (lbp) and lifting technique - a review. International Journal of Industrial Ergonomics 19(1): 59-74,

Strait, L., Inman, V. \& Ralston, H. (1947). Sample illustrations of physical principles selected from physiology and medicine American Journal of Physics 15: 375-382, 0002-9505

Thelen, E. (1989). The (re) discovery of motor development: Learning new things from an old field Developmental Psychology 25(6): 946-949,

Toussaint, H., De Winter, A., De Haas, Y., De Looze, M., Van Die N, J. \& Kingma, I. (1995). Flexion relaxation during lifting: Implications for torque production by muscle activity and tissue strain at the lumbo-sacral joint Journal of biomechanics 28(2): 199210 ,

Umphred, D. (1995). Neurological rehabilitation (Third Edition), Mosby-Year Book Inc, Saint Louis, $\mathrm{MO}$

Waters, T. R., Putz-Anderson, V., Garg, A. \& National Institute For, O. (1994). Applications manual for the revised niosh lifting equation US Dept. of Health and Human Services, Public Health Service, Centers for Disease Control, National Institute for Occupational Safety and Health, Division of Biomedical and Behavioral Science For sale by $\mathrm{NIOSH}$,

Wilke, H., Neef, P., Hinz, B., Seidel, H. \& Claes, L. (2001). Intradiscal pressure together with anthropometric data-a data set for the validation of models Clinical Biomechanics 16: 111-126,

Wilke, H. J., Neef, P., Caimi, M., Hoogland, T. \& Claes, L. E. (1999). New in vivo measurements of pressures in the intervertebral disc in daily life Spine 24(8): 755, 0362-2436

Zatsiorsky, V. (2002). Kinetics of human motion Human Kinetics Publishers, Champaign, IL 


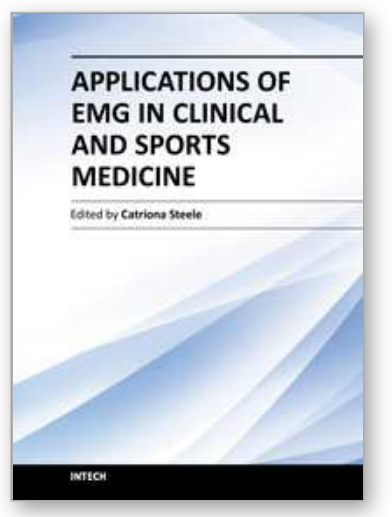

\author{
Applications of EMG in Clinical and Sports Medicine \\ Edited by Dr. Catriona Steele
}

ISBN 978-953-307-798-7

Hard cover, 396 pages

Publisher InTech

Published online 11, January, 2012

Published in print edition January, 2012

This second of two volumes on EMG (Electromyography) covers a wide range of clinical applications, as a complement to the methods discussed in volume 1. Topics range from gait and vibration analysis, through posture and falls prevention, to biofeedback in the treatment of neurologic swallowing impairment. The volume includes sections on back care, sports and performance medicine, gynecology/urology and orofacial function. Authors describe the procedures for their experimental studies with detailed and clear illustrations and references to the literature. The limitations of SEMG measures and methods for careful analysis are discussed. This broad compilation of articles discussing the use of EMG in both clinical and research applications demonstrates the utility of the method as a tool in a wide variety of disciplines and clinical fields.

\title{
How to reference
}

In order to correctly reference this scholarly work, feel free to copy and paste the following:

Jefferson Fagundes Loss, Débora Cantergi, Fábia Milman Krumholz, Marcelo La Torre and Claudia Tarragô Candotti (2012). Evaluating the Electromyographical Signal During Symmetrical Load Lifting, Applications of EMG in Clinical and Sports Medicine, Dr. Catriona Steele (Ed.), ISBN: 978-953-307-798-7, InTech, Available from: http://www.intechopen.com/books/applications-of-emg-in-clinical-and-sports-medicine/evaluating-theelectromyographical-signal-during-symmetrical-load-lifting

\section{INTECH}

open science | open minds

\author{
InTech Europe \\ University Campus STeP Ri \\ Slavka Krautzeka 83/A \\ 51000 Rijeka, Croatia \\ Phone: +385 (51) 770447 \\ Fax: +385 (51) 686166 \\ www.intechopen.com
}

\author{
InTech China \\ Unit 405, Office Block, Hotel Equatorial Shanghai \\ No.65, Yan An Road (West), Shanghai, 200040, China \\ 中国上海市延安西路65号上海国际贵都大饭店办公楼 405 单元 \\ Phone: +86-21-62489820 \\ Fax: +86-21-62489821
}


(C) 2012 The Author(s). Licensee IntechOpen. This is an open access article distributed under the terms of the Creative Commons Attribution 3.0 License, which permits unrestricted use, distribution, and reproduction in any medium, provided the original work is properly cited. 